\title{
Ameliorative Potential of Aminophylline In Restrain Stress Induced Behavioural and Biochemical Alterations
}

\author{
RAJNEET KAUR ${ }^{1}$, MANJINDER KAUR ${ }^{2}$ AND POONAM ARORA ${ }^{2}$ \\ ${ }^{1}$ Chitkara College of Pharmacy, Chitkara University, Rajpura, Punjab, India \\ ${ }^{2}$ G.H.G Khalsa College of Pharmacy, Gurusar Sadhar, Ludhiana, Punjab, India \\ *Email: rajneet.manchanda@gmail.com
}

Received: May 12, 2017 I Revised: June 16, 2017 I Accepted: August 18, 2017

Published online: Nov. 02, 2017

The Author(s) 2017. This article is published with open access at www.chitkara.edu.in/publications

\begin{abstract}
This study is designed to investigate the attenuating prospective of aminophylline in immobilization stress generated behavioural changes in rats. Animals were exposed to restrain stress before being subjected to varying doses of aminophylline $(1 \mathrm{mg} / \mathrm{kg}, 2 \mathrm{mg} / \mathrm{kg}$ and $4 \mathrm{mg} / \mathrm{kg})$. Behavioural changes were analyzed to assess the intensity and the degree of the stress, by estimating the changes in the exploratory behaviour, spontaneous activity and social behaviour using various paradigms. As a consequence of stress, the behavioral patterns so changed were assessed in the terms of changes in the locomotor activity, number of head dips and increased avoidance behaviour. Aminophylline $(4 \mathrm{mg} / \mathrm{kg})$ modulated the stress produced changes in the behaviour and oxidative stress generated biochemical alterations in a significant manner $(\mathrm{p}<0.001)$. The results so obtained suggest that upon exposure to stress, animal behavioural patterns, biochemical markers levels changed and these changes wereefficiently modulated by aminophylline at therapeutic doses.
\end{abstract}

Keywords: Aminophylline, Behavioural alterations, Biochemical alterations, Restraint stress.

\section{INTRODUCTION}

Stress has a complex neurobiology which involves release of stressor hormones (adrenocorticotrophin releasing hormone (ACTH), Nor-adrenaline (NA)) which further mediate the stress responses. Chronic stress leads to depression. In Depression, there is a release of mediators which are proinflammatory in nature, mainly cytokinesTNF- $\alpha$, IL-1, IL-6 and IFN- $\gamma$ ) in

Journal of Pharmaceutical Technology, Research and Management Vol-5, No-2, November 2017 pp. $117-133$ 
Kaur, R.

Kaur, M.

Arora, $\mathrm{P}$. brain, which consequently provoke the HPA- axis. Triggering of the HPAaxis, causes the release of Adrenocoticotrophin hormone, which manifests the changes in the behaviour as a response to stress(Miller et al. 2009). Release of NA and over activity of $\alpha$ and $\beta$ receptors in brain, another effect produced in response to stress promotes the levels of cytokines in brain( Johnson et al. 2005).

It has been reported that stressful conditions result in the activation of TNF- $\alpha$ in brain. TNF- $\alpha$ being a neuro-inflammatory mediator (Alleva et al.1993, Calamandrei et al. 1991) triggers a neuro-inflammatory cascade which results in enhanced expression of cyclo-oxygenase-2 (COX-2) enzyme (Nogawa et al.1997). Increased levels of COX-2 results in production of prostaglandin, $\mathrm{PGE}_{2}$, which promotes febrile and behavioral alterations (Vesce et al. 2007).

Aminophylline a competitive non selective phosphodiesterase inhibitor which has been remarkably used in the treatment of acute and chronic bronchial asthma, apnea syndromes, COPD, in treatment of bradyarrythmias in elderly (Vassallo and Lipsky, 1998). Another astonishing use of theophylline is the induction of the apoptosis in the chronic lymphocytic leukemia cells along with chlorambucil. Recently, aminophylline has been investigated as a potential adjunct along with furosemide in increasing urine output in fluid overloaded patients.

The activity of aminophylline is due to its metabolic product, theophylline. Theophylline has multiple mechanism of action which includes phosphodiesterase enzyme inhibition, adenosine receptor antagonism and immunomodulatory effects(Vassallo and Lipsky, 1998). The antiinflammatory activity is attributed to modulation of cytokine production. Exposure to theophylline, triggers an increase in the levels of IL-10, an antiinflammatory cytokine, which exerts an inhibitory control over the production of the pro-inflammatory cytokines (IL-2, IFN- $\gamma$, IL-5, TNF- $\alpha$ and IL-8). Thus it can be proposed that the compounds which either promote the production of anti-inflammatory cytokines or the one blocking the inflammatory effects of pro-inflammatory cytokines can be a potential target for modulation of restrain stress generated oxidative stress mediated inflammation and the resultant behavioural alterations. However, the anti-stress potential of aminophylline is not yet investigated, despite its significant potential to inhibit TNF- $\alpha$. Thus, this study focuses on the investigation of the attenuating potential of aminophylline in restrain stress generated behavioral alterations in rats. The alterations of reduced glutathione, lipid peroxidase, catalase and superoxide dismutase in the restrain stress induced animals was also studied to determine the biochemical basis of the anti-stress mechanism of aminophylline. 


\section{MATERIALS AND METHODS}

\subsection{Animals}

Sprague Dawley rats of female sex, in frank oestrus stage, (Kaur et al. 2010, Manchanda et al. 2011,) weighing 150-250 g, were used inthis study. Animals were fed on standard laboratory diet and animals were housed in the Departmental animal house, Chitkara college of Pharmacy, Chitkara University, Punjab. They were exposed to natural cycles of light and dark. Care of the animals was carriedout as per the guidelines of the Committee for the Purpose of Control and Supervision of Experimental Animals (CPCSEA) and the experimental protocol was approved by the Institutional Animal Ethics Committee.

\subsection{Drugs and Chemicals}

Aminophylline, used in the study, was available as (anhydrous) aminophylline from AartiIndustries Limited, Jalandhar, India. Other chemicals employed in the study were of analytical grade and purchased from Sigma Aldrich, U.S.A and SDFCL (SD-Fine Chemical Limited, Mumbai).

\subsection{Experimental Procedure}

\subsubsection{Induction of Restrain Stress}

A wire mesh restrainer was used to induce restrain stress. Dimensions of the restrainer were $11 \mathrm{~cm} \times 8 \mathrm{~cm} \times 8 \mathrm{~cm}$ and the animals were subjected to immobilization for 3.5 hours (Madhyastha et al. 2008). The restrainer had a wooden base and stainless steel wire mesh hinged to the base. The restrainer restricts the movement of the animals without producing any sort of discomfort and pain.

\subsection{Behavioral Measurements}

Prior Acclimatization of rats was done on each test, 5 min daily for 3 days. The rats were then subjected to restrain stress, and then chain of behavioral tests was performed in animals beginning with the estimation of index of curiosity to the social behaviour of the animal with a gap of $5 \mathrm{~min}$ between each test. The experimental protocol was carried out in early morning as the corticosterone levels are at peak in the morning. The behavioural models so employed in the study were cleaned using alcohol.

\subsubsection{Hole board test}

This test is used for the measurement of the curiosity of the animal to explore the surroundings. Hole board is made up of a wooden box of the dimensions
Ameliorative

Potential of

Aminophylline

In Restrain

Stress Induced

Behavioural and

Biochemical

Alterations 
Kaur, R. Kaur, M. Arora, $\mathrm{P}$.

$68 \mathrm{~cm} \times 68 \mathrm{~cm}$ with the walls $40 \mathrm{~cm}$ high. The box was placed on a stand at a height of $28 \mathrm{~cm}$ from the ground. The holes (4 in number of diameter $4 \mathrm{~cm}$ ) were $28 \mathrm{~cm}$ away from the corners of the box and using tape the floor of the box was divided into one central and four peripheral areas. Tape was used to mark the boundaries into four peripheral areas and one mid area. The mid area was marked by tape from the four sides in such a way that the distance between the central area and the walls is $20 \mathrm{~cm}$ and the peripheral areas are marked diagonally. The four holes lie at the corners of the central area. Behavioural parameters measured in hole board are number of head dips and the incidence of rearing(Brown and Nemes, 2008).

\subsubsection{Open field test}

This test is used to assess the alertness and index of curiosity. The apparatus used for the open field test is made up of wooden box measured $90 \mathrm{~cm} \times$ $90 \mathrm{~cm} \times 38 \mathrm{~cm}$. The walls are darkened using black paintand the floor is painted white (Blokland et al. 2002; Roman et al. 2006). Floor of the box was partitioned into 16 marginal and 9 central small squares(in total there were 25 squares) of dimensions $17 \mathrm{~cm} \times 17 \mathrm{~cm}$. Number of line crossing and the time spent in the peripheral and central areas were measured by placing the animal in the centre of the wooden box for $10 \mathrm{~min}$.

\subsubsection{Social interaction test}

Social interaction test is done in the open field box. Time of avoidance and following are noted in seconds for an interval of $10 \mathrm{~min}$ by placing the animals in the center of the box (Rex et al. 2004; Toth et al., 2008). Nonsocial behavior(Aggressive behavior such as boxing, biting or threatening the partner rat apart from self-grooming/ignoring the partner) and social behaviour(following other rats) are well characterized during assessment of $10 \mathrm{~min}$.

\subsection{Biochemical Estimations}

\subsubsection{Tissue Homogenate preparation}

Biochemical analysis was done using brain tissue homogenate, which was prepared by removing the brain from the sacrificed animal. After the behavioural parameters assessment, animals were decapitated and the brain was removed and a tissue homogenate of $10 \%(\mathrm{w} / \mathrm{v})$ in $0.1 \mathrm{M}$ phosphate buffer ( $\mathrm{pH}$ 7.4). This homogenate was then centrifuged for $15 \mathrm{~min}$ at a speed of $10,000 \mathrm{rpm}$. The clear supernatant so obtained is employed for different biochemical estimations(Kumar et al., 2009). 


\subsubsection{Estimation of Reduced Glutathione}

Reduced Glutathione (GSH) is a powerful antioxidant. Immobilization stress results in generation of oxidative stress and consequently, free radicals are also generated. Glutathione is capable of scavenging Reactive Oxygen Species (Harris, 1992).Homogenate is mixed with equal volume of $20 \%$ tricholoroacteic acid (TBA) which contains $1 \mathrm{mM}$ EDTA, which causes precipitation of tissue proteins. Then this mixture is subjected to centrifugation at $200 \mathrm{rpm}$ for 10 min. To this $200 \mu \mathrm{l}$ of the supernatant, $1.8 \mathrm{ml}$ of Ellman's reagent (5, 5' $\square$ dithio bis2-nitrobenzoic acid- $0.01 \mathrm{M}$ prepared in $0.3 \mathrm{M}$ phosphate buffer with $1 \%$ of sodium citrate soluon). The volume in the test tubes is then made up to $2 \mathrm{ml}$. The mixture is then analysed at UV spectrophotometer at $412 \mathrm{~nm}$ against blank and the result is expressed in micromole/g brain. The absorbance values of the test sample were compared with the standard curve of GSH(Ellman, 1959).

\subsubsection{Estimation of lipid peroxidase}

Oxidative stress, generated as a result of restrains stress results in lipid peroxidation and cell damage. Peroxidation product, Thiobarbituric Acid Reacting Substances (TBARS), serves as a specific indicator (Das et al. 2000). For the measurement of the TBARS $0.5 \mathrm{ml}$ of tissue homogenateis mixed with $0.5 \mathrm{ml}$ tris HCL ( $\mathrm{pH} \mathrm{7.4).} \mathrm{The} \mathrm{above} \mathrm{mixture} \mathrm{is} \mathrm{then} \mathrm{incubated} \mathrm{at} 37^{\circ} \mathrm{C}$ for 2 hours, and then $1 \mathrm{ml} 1 \mathrm{ml}$ of ice cold $10 \%$ TCA is added. Centrifugation of the mixture is done for $10 \mathrm{~min}$ at $1000 \mathrm{rpm}$ speed. The supernatant so obtained is collected and to this $1 \mathrm{ml}$ of $0.67 \%$ TBA is added. The above mixture is then heated for $10 \mathrm{~min}$ in a water bath and cooled. Finally, $1 \mathrm{ml}$ of distilled water is added and then optical density is measured taking distilled water as blank at $532 \mathrm{~nm}$ (Wills, 1996).

\subsubsection{Estimation of catalase}

Another endogenous antioxidant that catalyses the dismutation of hydrogen peroxide into water and oxygen is a haem-containing enzyme called as catalase. It decreases the level of free radicals which are generated due to restrain stress (Deisseroth and Dounce, 1970). For the estimation of the catalase, $3 \mathrm{~mL}$ of $\mathrm{H}_{2} \mathrm{O}_{2}$ in phosphate buffer is added to $0.05 \mathrm{ml}$ of the homogenate and the absorbance is measured at $240 \mathrm{~nm}$. Results are expressed as micromole $\mathrm{H}_{2} \mathrm{O}_{2}$ decomposed per $\mathrm{mg}$ of protein/min (Luck, 1971).

\subsubsection{Estimation of superoxide dismutase}

Superoxide Dismutase (SOD) isan important endogenous antioxidant enzyme and catalyzes the dismutation of the highly reactive superoxide anion to oxygen and to the less reactive species hydrogen peroxide(Fridovich, 1983; Willcox
Ameliorative

Potential of

Aminophylline

In Restrain

Stress Induced

Behavioural and

Biochemical

Alterations

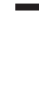


Kaur, R. Kaur, M. Arora, $\mathrm{P}$.

et al. 2004). To estimate superoxide dismutase, $2 \mathrm{ml}$ of NBT (Nitrobluetetrazolium) is added to $0.5 \mathrm{ml}$ hydroxylamine $\mathrm{HCl}$ and then $0.1 \mathrm{ml}$ of homogenate is added. Change in the absorbance was recorded using distilled water as blank at $560 \mathrm{~nm}$ for $2 \mathrm{~min}$ at $30 / 60 \mathrm{sec}$ intervals.

\subsection{Experimental Protocol}

Seven groups, comprising five Sprague Dawley female rats were employed in the present study.

\section{Group I: Normal control}

The rats are not given any type of stressors, behavioural parameters were noted. A sequence was set up for the behavioural assessment starting with the hole board followed by the open field test and social interaction test. After the behavioural assessment, tissue homogenates were prepared for biochemical analysis by sacrificing the animals

\section{Group II: Stress control group}

In this group, the animals were exposed to restrain stress for three and half hours. Thereafter, behavioural parameters were estimated in a sequential manner. Then the tissue homogenates were prepared for analyzing various biochemical parameters.

\section{Group III: Aminophylline $(1 \mathrm{mg} / \mathrm{kg})+$ stress control group}

In this group, the animals were pretreated with Aminophylline ( $1 \mathrm{mg} / \mathrm{kg}$ i.p.) $30 \mathrm{~min}$ prior to exposure to stress. The animals were then exposed to stress (3.5 hours). Thereafter, behavioural parameterswere estimated in a sequential manner. Then the tissue homogenates were prepared for analyzing various biochemical parameters.

Group IV: Aminophylline $(2 \mathrm{mg} / \mathrm{kg})+$ stress control group

In this group, the animals were pretreated with Aminophylline ( $2 \mathrm{mg} / \mathrm{kg}$ i.p.) $30 \mathrm{~min}$ prior to exposure to stress. The animals were then exposed to stress (3.5 hours). Thereafter, behavioural parameters were estimated in a sequential manner. Then the tissue homogenates were prepared for analyzing various biochemical parameters.

Group V: Aminophylline $(4 m \mathrm{~g} / \mathrm{kg})+$ stress control group

In this group, the animals were pretreated with Aminophylline (4 mg/kg i.p.) $30 \mathrm{~min}$ prior to exposure to stress. The animals were then exposed to stress 
(3.5 hours). Thereafter, behavioural parameters were estimated in a sequential manner. Then the tissue homogenates were prepared for analyzing various biochemical parameters.

\section{Group VI: Aminophylline (4 $\mathrm{mg} / \mathrm{kg}$ per se)}

In this group, the animals were not exposed to restrain stress, but aminophylline $(4 \mathrm{mg} / \mathrm{kg}$ i.p.) was administerd to the rats to assess the per se effect of aminophylline. Thereafter, behavioural parameterswere estimated in a sequential manner. Then the tissue homogenates were prepared for analyzing various biochemical parameters.

Group VII: Diazepam $(2 \mathrm{mg} / \mathrm{kg})+$ stress control group

In this group, the animals were pretreated with Diazepam ( $2 \mathrm{mg} / \mathrm{kg}$ i.p. $) 30$ min prior to exposure to stress. The animals were then exposed to stress (3.5 hours). Thereafter, behavioural parameters were estimated in a sequential manner. Then the tissue homogenates were prepared for analyzing various biochemical parameters.

\subsection{Statistical Analysis}

The results were expressed as Mean \pm Standard Error of Means (S.E.M.). The results were analyzed using one-way ANOVA followed by post-hoc analysis using Tukey's Multiple Comparison Test for comparison between different groups. The $\mathrm{p}$ value $<0.0001,<0.01,<0.05$ was considered to be statistically significant.

\section{RESULTS}

\subsection{Consequence of immobilization stress and aminophylline on exploratory behaviour of rats(head dips and rearing) in Hole board test}

Index of curiosity or exploration, in hole board test is analyzed by number of head dips and the frequency of rearing. The rats subjected to restrain stress, had a decreased exploratory behavior as indexed by the number of head dips and rearing in comparison to the normal control group. Pretreatment with aminophylline ( $1 \mathrm{mg} / \mathrm{kg}, 2 \mathrm{mg} / \mathrm{kg}$, and $4 \mathrm{mg} / \mathrm{kg}$ i.p.), however had a modulating effect on the behavior of the animal as depicted by a significant increase in the number o head dips and rearing as compared to the stress control group. Aminophylline $(4 \mathrm{mg} / \mathrm{kg}$ i.p) had a significant attenuating effect on the behavioural alteration produced by restrain stress which was comparable to the standard drug (Figure 1 and 2).
Ameliorative

Potential of

Aminophylline

In Restrain

Stress Induced

Behavioural and

Biochemical

Alterations 
Kaur, R.

Kaur, M.

Arora, P.

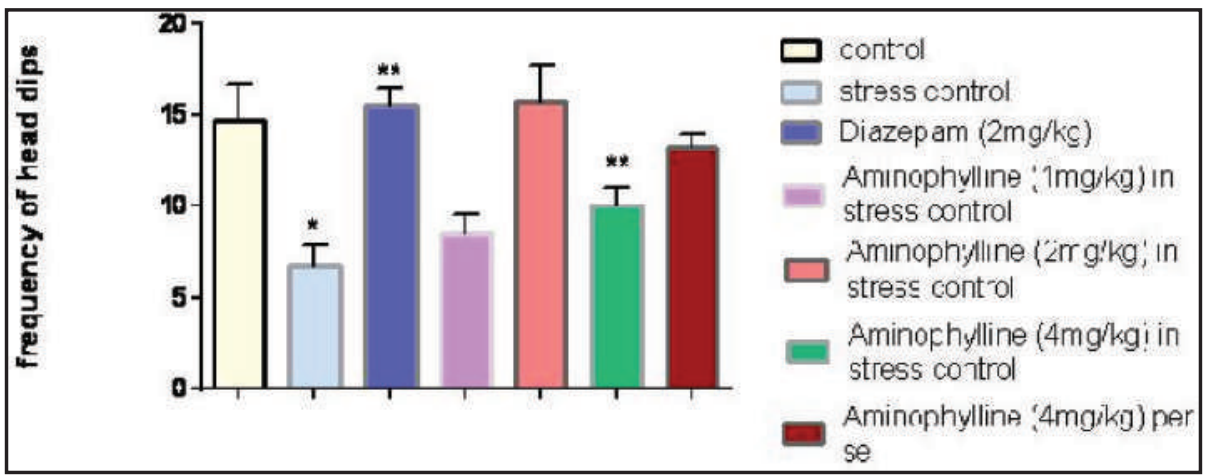

Figure 1: Effect of restrain stress and aminophylline on frequency of head dips in the hole board test. Values are expressed as mean \pm S.E.M $* * \mathrm{P}<0.001$ as compared to normal control group, $* * * \mathrm{P}<0.001$ as compared to stress control group, ${ }^{* *} \mathrm{P}<0.01$ as compared to stress control group, ${ }^{*} \mathrm{P}<0.05$ as compared to diazepam in stress control group.

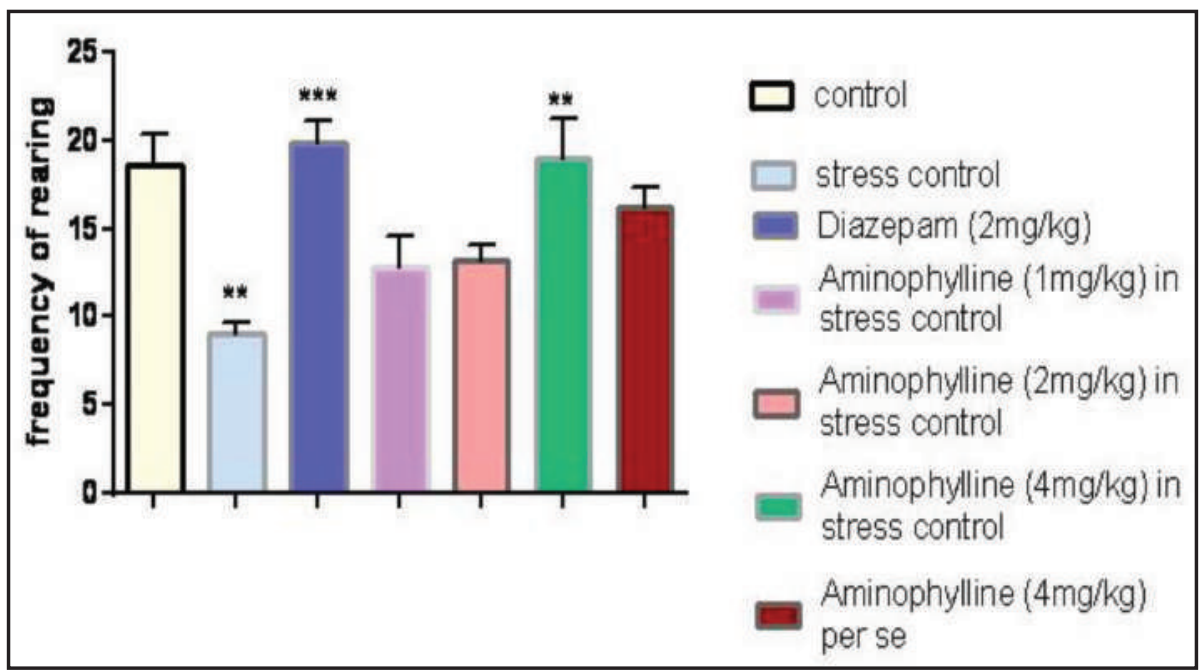

Figure 2: Effect of restrain stress and aminophylline on frequency of rearing in the hole board test. Values are expressed as mean \pm S.E.M $* * \mathrm{P}<0.01$ as compared to normal control group, $* * * \mathrm{P}<0.001$ as compared to stress control group, $* \mathrm{P}<0.05$ as compared to diazepam, $* \mathrm{P}<0.05$ as compared to stress control group. 


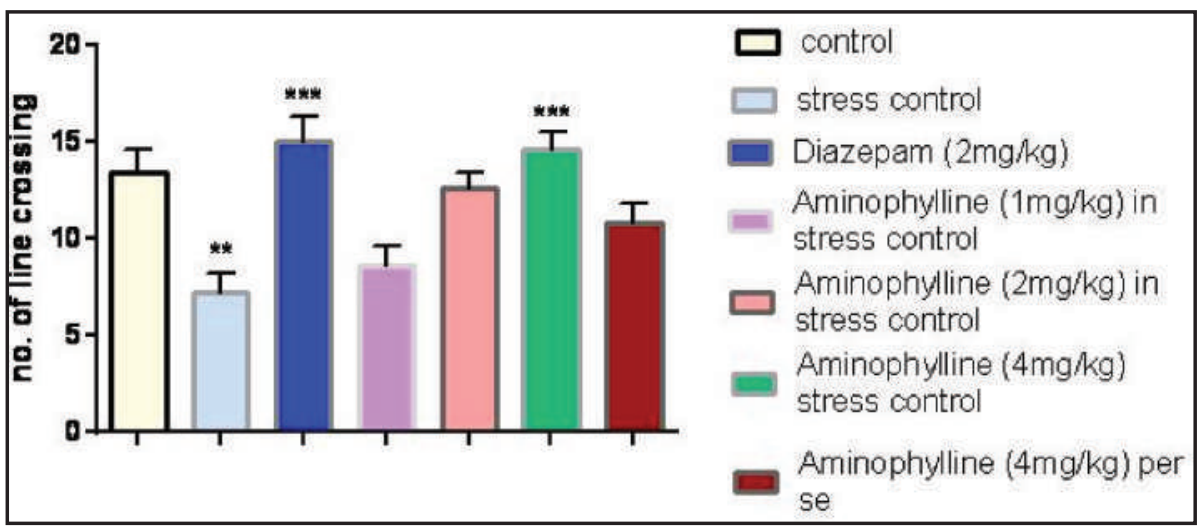

Ameliorative

Potential of

Aminophylline

In Restrain

Stress Induced

Behavioural and

Biochemical

Alterations

Figure 3: Effect of restrain stress and aminophylline on frequency no. of line crossing in open field test. Values are expressed as mean \pm S.E.M $* * \mathrm{P}<0.01$ as compared to normal control group, $* * * \mathrm{P}<0.001$ as compared to stress control group, $* * \mathrm{P}<0.01$ as compared to stress control group, $* * * \mathrm{P}<0.001$ as compared to diazepam in stress control group.

Table 1: Effect of restrain stress and aminophylline on line crossing and rearing on open field test. Statistically analyzed by one-way analysis of variance (ANOVA) followed by post-hoc analysis using Tukey's Multiple Comparison Test. Values are expressed as Mean \pm S.E.M with $\mathrm{n}=5$ in each group. $* * \mathrm{P}<0.01$ as compared to normal control group, $* * * \mathrm{P}<0.001$ as compared to stress control group, $* * \mathrm{P}<0.01$ as compared to stress control group, $* \mathrm{P}<0.05$ as compared to diazepam in stress control group.

\begin{tabular}{lcc}
\hline Experimental Groups & Line crossing & Rearing \\
\hline Normal control & $13.4 \pm 1.2$ & $12 \pm 1.67$ \\
Stress control & $7.2 \pm 1.0^{* *}$ & $5.50 \pm 1.00^{* *}$ \\
Diazepam $(2 \mathrm{mg} / \mathrm{kg})$ & $15.0 \pm 1.30^{* * *}$ & $1.3 \pm 1.1^{* * *}$ \\
Aminophylline $(1 \mathrm{mg} / \mathrm{kg})$ in stress control group & $8.6 \pm 1.0^{* *}$ & $7.0 \pm 0.11$ \\
Aminophylline $(2 \mathrm{mg} / \mathrm{kg})$ in stress control group & $12.6 \pm 0.8$ & $10 \pm 1$ \\
Aminophylline $(4 \mathrm{mg} / \mathrm{kg})$ in stress control group & $14.6 \pm 0.9^{* * *}$ & $12.15 \pm 1.67 * *$ \\
Aminophylline $(4 \mathrm{mg} / \mathrm{kg})$ per se & $10.8 \pm 10$ & $13.25 \pm 0.68$ \\
\hline
\end{tabular}

3.2 Effect of immobilization stress and aminophylline on spontaneous activity and exploratory behaviour) in open field test:

Motor activity and exploration are articulated as number of line crossing and the frequency of rearing. The rats subjected to restrain stress, had a decreased 
Kaur, R.

Kaur, M.

Arora, P.

exploratory behavioras expressed by the number of rearing in comparison to the normal control group. The index of wakefulness is indicated by the motor activity, which significantly decreases in the restrain stress group as compared to the group of animals not subjected to stress( normal control group). Pretreatment with aminophylline $(1 \mathrm{mg} / \mathrm{kg}, 2 \mathrm{mg} / \mathrm{kg}$, and $4 \mathrm{mg} / \mathrm{kg}$ i.p.), however had a modulating effect on the behavior of the animal as depicted by a significant increase in the number of rearing and line crossing as compared to the stress control group. Aminophylline ( $4 \mathrm{mg} / \mathrm{kg}$ i.p) had a significant attenuating effect on the behavioural alteration produced by restrain stress which was comparable to the standard drug(Figure 3 and 4, Table 1).

\subsection{Effect of immobilization stress and aminophylline on rats in social interaction test:}

The social behaviour and the non- social behaviour is analyzed by determining the average time of following and avoidance in the social interaction test. In case of pretreatment with aminophylline $(1 \mathrm{mg} / \mathrm{kg}, 2 \mathrm{mg} / \mathrm{kg}$ and $4 \mathrm{mg} / \mathrm{kg}$ i.p) protocols, time of following the partner (social behavior) was primarily shown, while in the restrain stress group time of avoidance was shown mainly (Table 2).

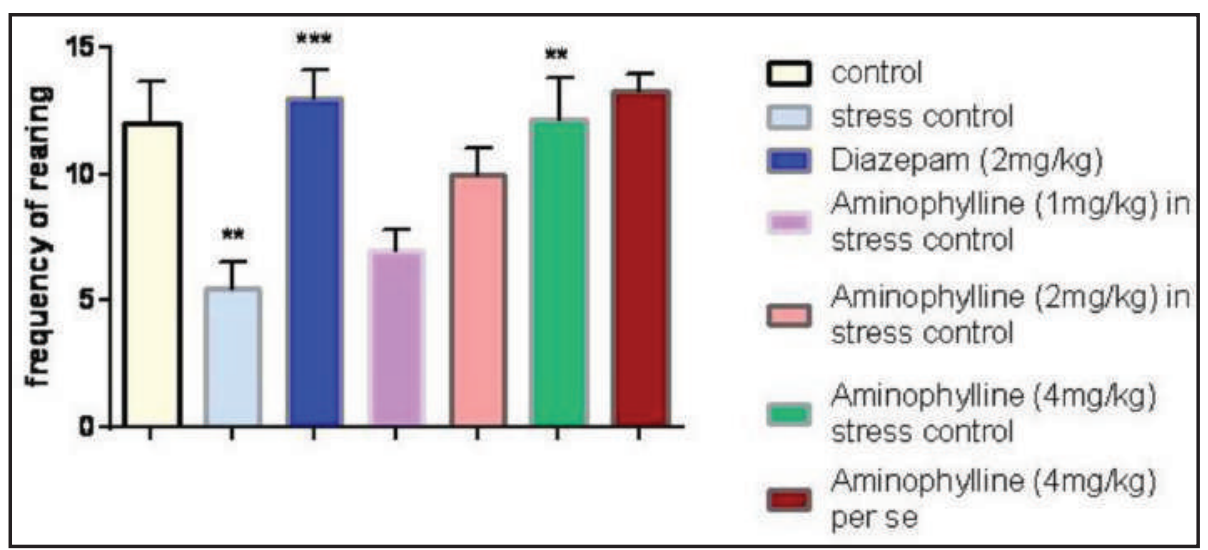

Figure 4: Effect of restrain stress and aminophylline on frequency no. of rearing in open field test. Values are expressed as mean \pm S.E.M $* * \mathrm{P}<0.01$ as compared to normal control group, $* * * \mathrm{P}<0.001$ as compared to stress control group, $* \mathrm{P}<0.05$ as compared to stress control group, $* \mathrm{P}<0.05$ as compared to diazepam in stress control group. 


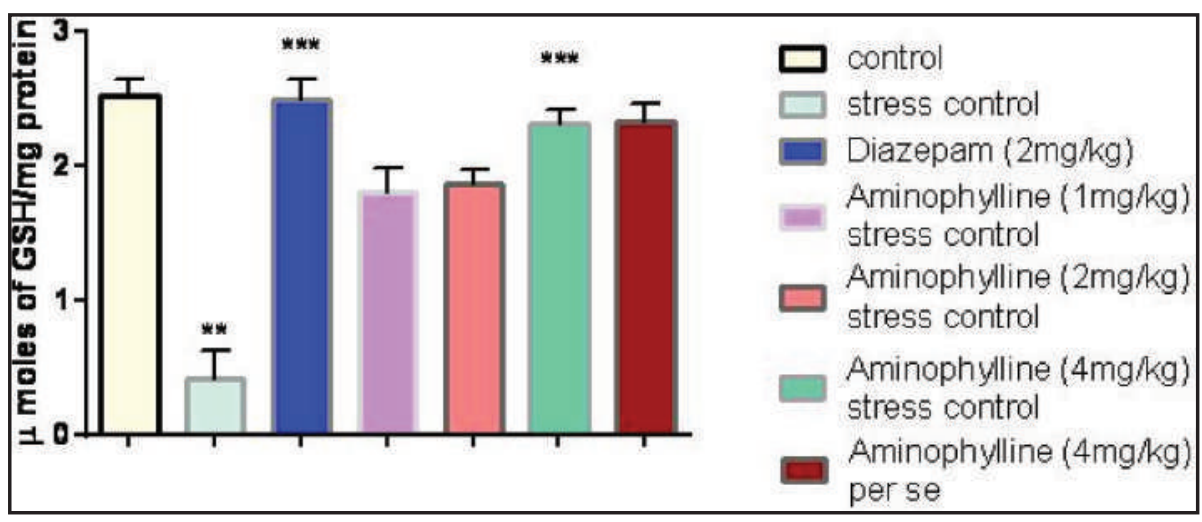

Ameliorative

Potential of

Aminophylline

In Restrain

Stress Induced

Behavioural and

Biochemical

Alterations

Figure 5: Effect of restrain stress and aminophylline on changes in reduced glutathione levels (GSH). Results are represented as the mean \pm S.E.M. with $\mathrm{n}=5$ in each group, $* \mathrm{P}<0.05$ as compared to normal control group.

Table 2: Effect of restrain stress and aminophylline on the time of following and avoidance (s) in the social interaction test. Values are expressed as Mean \pm S.E.M with $\mathrm{n}=5$ in each group. ${ }^{*} * \mathrm{P}<0.01$ as compared to normal control group, $* \mathrm{P}<0.05$ as compared to stress control group, $* \mathrm{P}<0.05$ as compared to diazepam in stress control group.

\begin{tabular}{lcc}
\hline Experimental Groups & Time of following (s) & Time of avoidance (s) \\
\hline Normal control & $3.83 \pm 0.79$ & $5 \pm 1.23$ \\
Stress control & $4.5 \pm 0.76^{*}$ & $6 \pm 0.81^{*}$ \\
Diazepam $(2 \mathrm{mg} / \mathrm{kg})$ & $3.5 \pm 0.670^{*}$ & $7.5 \pm .118^{*}$ \\
Aminophylline $(1 \mathrm{mg} / \mathrm{kg})$ in stress control & $3.33 \pm 0.61$ & $7.66 \pm 0.802$ \\
Aminophylline $(2 \mathrm{mg} / \mathrm{kg})$ in stress control & $3.5 \pm 0.288$ & $5 \pm 1$ \\
Aminophylline $(4 \mathrm{mg} / \mathrm{kg})$ in stress control & $1.33 \pm 0.49^{* *}$ & $8 \pm 0.516^{* *}$ \\
Aminophylline $(4 \mathrm{mg} / \mathrm{kg})$ per se & $1.5 \pm 0.670$ & $3.5 \pm 0.763$ \\
\hline
\end{tabular}

\subsection{Alterations in the reduced glutathione in immobilization stress and pretreatment with aminophylline groups.}

Reduced glutathione levels decreased as a consequence of immobilizationstress in contrast to the normal control group. Pretreatment with aminophylline ( $1 \mathrm{mg} / \mathrm{kg}, 2 \mathrm{mg} / \mathrm{kg}$ and $4 \mathrm{mg} / \mathrm{kg}$ i.p.) increased the brain Reduced glutathione levels in a dose dependent manner. (Figure 5 and Table 3). 
Kaur, R.

Kaur, M.

Arora, P.

\subsection{Alterations in the Lipid Peroxidation (LPO) level due to restrain stress and aminophylline}

Thiobarbituric acid reacting substances (TBARS) levels, was increased, in the brain of the rats subjected to restrain stress when compared with the normal control group. Aminophylline ( $1 \mathrm{mg} / \mathrm{kg}, 2 \mathrm{mg} / \mathrm{kg}$ and $4 \mathrm{mg} / \mathrm{kg}$ i.p.), in a dose dependant manner, has decreased the brain TBARS levels (Figure 6 and Table 3).

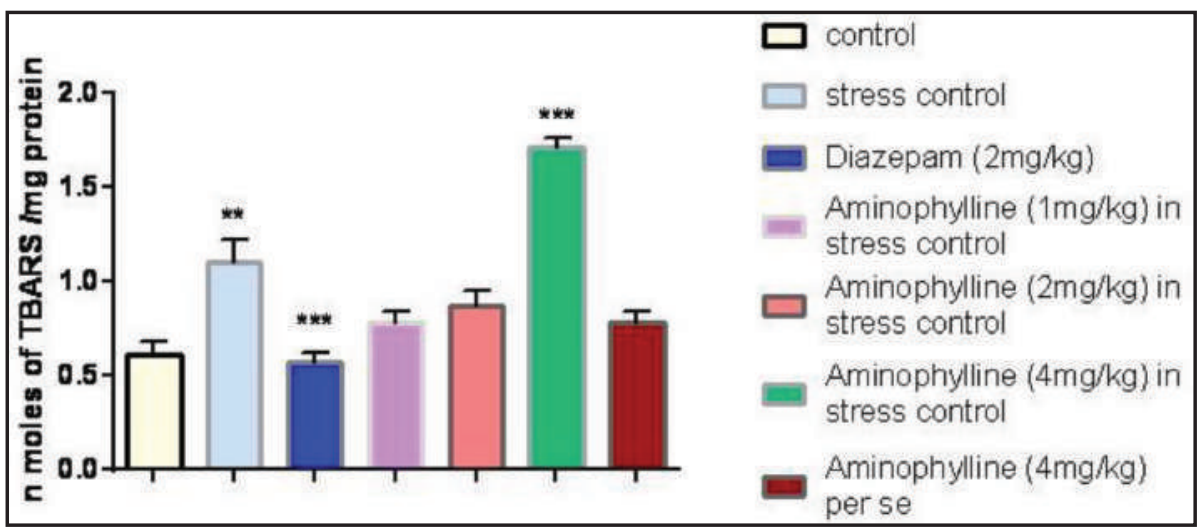

Figure 6: Effect of restrain stress and aminophylline on changes in Lipid Peroxidation (LPO) levels. Results are represented as the mean \pm S.E.M. with $n$ $=5$ in each group, ${ }^{*} * \mathrm{P}<0.01$ as compared to normal control group, ${ }^{*} * * \mathrm{P}<0.001$ as compared to stress control group, $* * \mathrm{P}<0.01$ as compared to diazepam.

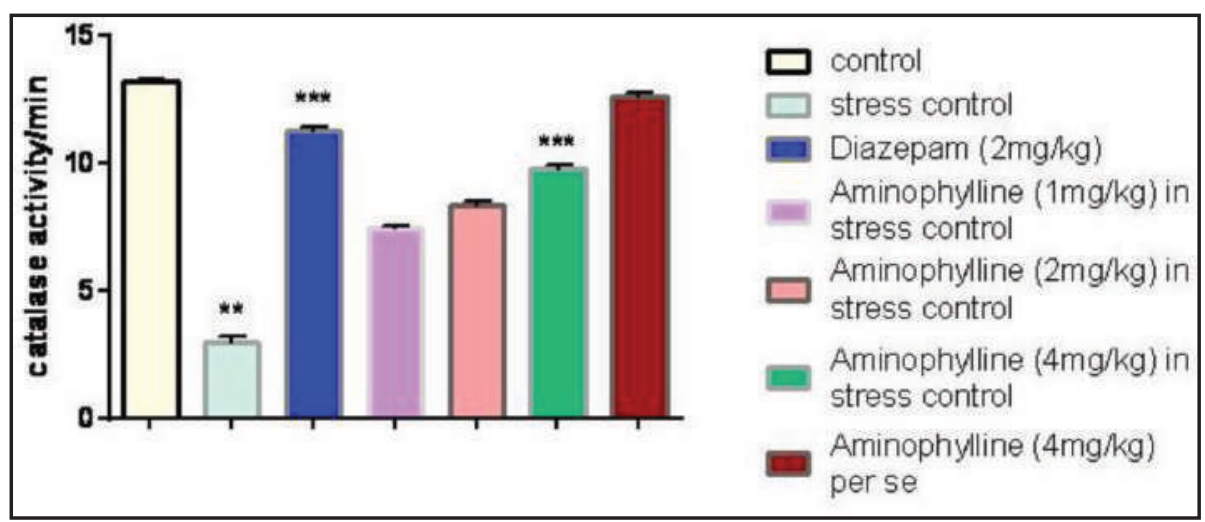

Figure 7: Effect of restrain stress and aminophylline on changes in catalase (CAT) levels. Results are represented as the mean \pm S.E.M. with $\mathrm{n}=5$ in each group, $* * * * \mathrm{P}<0.0001$ as compared to normal control group, $* * * * \mathrm{P}<0.0001$ as compared to stress control group, $* * * * \mathrm{P}<0.0001$ as compared to stress control group, $* * * * \mathrm{P}<0.0001$ as compared to diazepam. 
3.6 Changes in Catalase levels due to immobilization stress and aminophylline

Decreased brain catalase levels wereobserved in restrain stress. Aminophylline protocols $(1 \mathrm{mg} / \mathrm{kg}, 2 \mathrm{mg} / \mathrm{kg}$ and $4 \mathrm{mg} / \mathrm{kg}$ i.p.), dose dependently, significantly elevated the brain catalase levels (Figure 7 and Table 3).

Table 3: Effect of restrain stress and aminophylline on changes in biochemical parameters such as Lipid Peroxidation (LPO), Superoxide Dismutase (SOD), Reduced Glutathione (GSH) and Catalase (CAT). Statistically analyzed by One-Way Analysis of Variance (ANOVA) followed by post-hoc analysis using Tukey's Multiple Comparison Test. Values are expressed as Mean \pm S.E.M. with $\mathrm{n}=5$ in each group, $* * \mathrm{p}<0.01, * * * * \mathrm{p}<0.0001, * \mathrm{P}<0.05$ as compared to normal control group and $* * * \mathrm{p}<0.001, * * \mathrm{P}<0.01$ as compared to stress control group.

\begin{tabular}{|c|c|c|c|c|}
\hline $\begin{array}{l}\text { Experimental } \\
\text { Groups }\end{array}$ & $\begin{array}{c}\text { LPO } \\
(\mathrm{nmol} / \mathrm{mg} \text { protein })\end{array}$ & $\begin{array}{c}\text { SOD } \\
(\mu \mathrm{mol} / \mathrm{mg} \text { protein })\end{array}$ & $\begin{array}{c}\text { CAT } \\
(\mu \mathrm{mol} / \mathrm{mg} \text { protein })\end{array}$ & $\begin{array}{c}\text { GSH } \\
(\mu \mathrm{mol} / \mathrm{mg} \text { protein })\end{array}$ \\
\hline Normal control & $0.61 \pm 0.07$ & $2.63 \pm 0.12$ & $13.22 \pm 0.05$ & $2.52 \pm 0.12$ \\
\hline Stress control & $1.09 \pm 0.12^{* *}$ & $0.51 \pm 0.21^{* *}$ & $2.97 \pm 0.2 * *$ & $0.41 \pm 0.21 * *$ \\
\hline Diazepam $(2 \mathrm{mg} / \mathrm{kg})$ & $5.70 \pm 0.50 * * *$ & $2.49 \pm 0.16^{* * *}$ & $11.24 \pm 0.16^{* * *}$ & $2.49 \pm 0.16^{* * *}$ \\
\hline $\begin{array}{l}\text { Aminophylline } \\
(1 \mathrm{mg} / \mathrm{kg}) \text { in stress } \\
\text { control }\end{array}$ & $1.06 \pm 0.08$ & $1.81 \pm 0.14$ & $7.43 \pm 42.53$ & $1.8 \pm 0.144$ \\
\hline $\begin{array}{l}\text { Aminophylline } \\
(2 \mathrm{mg} / \mathrm{kg}) \text { in stress } \\
\text { control }\end{array}$ & $0.86 \pm 0.08$ & $1.96 \pm 0.10$ & $8.39 \pm 0.10$ & $2.31 \pm 0.11$ \\
\hline $\begin{array}{l}\text { Aminophylline } \\
(4 \mathrm{mg} / \mathrm{kg}) \text { in stress } \\
\text { control }\end{array}$ & $1.70 \pm 0.50 * * *$ & $2.21 \pm 0.11^{* * *}$ & $9.78 \pm 0.11^{* * *}$ & $2.33 \pm 0.14 * * *$ \\
\hline $\begin{array}{l}\text { Aminophylline } \\
(4 \mathrm{mg} / \mathrm{kg}) \text { per se }\end{array}$ & $0.78 \pm 0.6$ & $2.58 \pm 0.14$ & $12.65 \pm 0.14$ & $158.8 \pm 0.14$ \\
\hline
\end{tabular}

\subsection{Alterations in the Superoxide Dismutase (SOD) level due to restrain stress and aminophylline:}

Decreasedbrain superoxide dismutase (SOD) levels were observed in rats after exposure to restrain stress. Aminophylline protocols $(1 \mathrm{mg} / \mathrm{kg}, 2 \mathrm{mg} / \mathrm{kg}$ and $4 \mathrm{mg} / \mathrm{kg}$ i.p.), increased SOD levels significantly (Figure 8 and Table 3).
Ameliorative

Potential of Aminophylline

In Restrain

Stress Induced Behavioural and

Biochemical

Alterations 


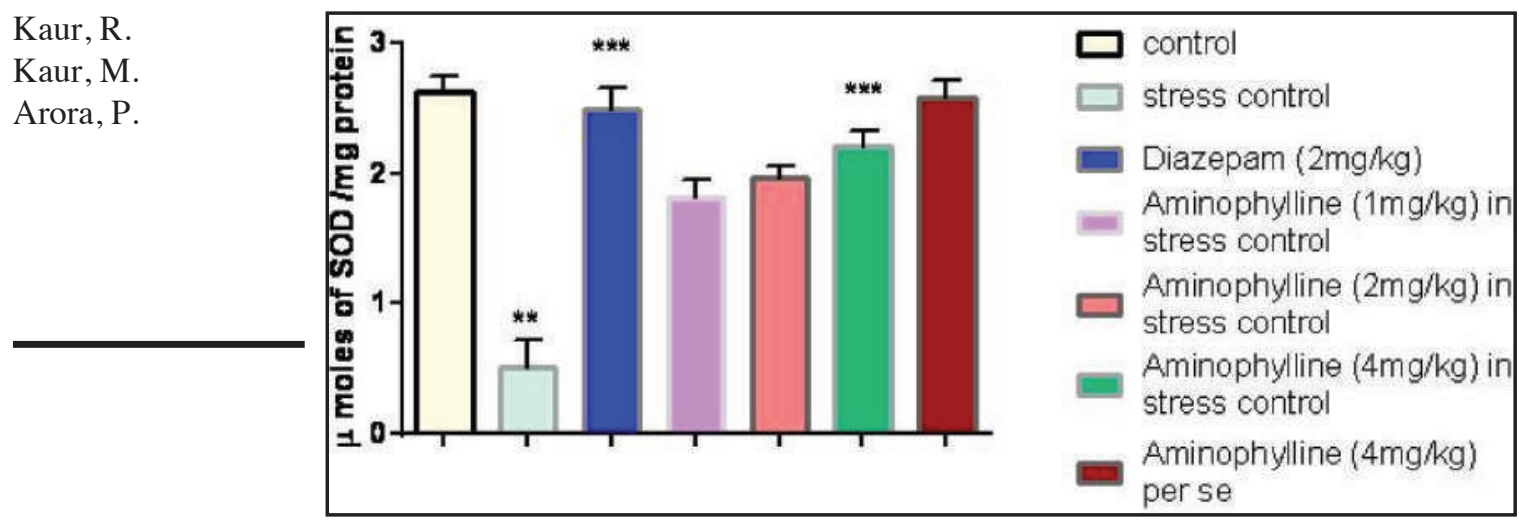

Figure 8: Effect of restrain stress and aminophylline on changes in Superoxide dismutase (SOD) levels. Results are represented as the mean \pm S.E.M. with $\mathrm{n}=5$ in each group, $* * * * \mathrm{P}<0.001$ as compared to normal control group, $* * * * \mathrm{P}<0.001$ as compared to stress control group, $* \mathrm{P}<0.05$ as compared to diazepam, $* * * * \mathrm{P}<0.01$ as compared to stress control group.

\section{DISCUSSION}

Aminophylline, being a compound of theophylline and ethylene diamine (85:15) gets converted into theophylline in-vivo (Abe et al. 2008). Theophylline is a inhibitor of phosphodiesterase enzyme andcauses an increase in intracellular cAMP which in turn activates protein kinase (pKA) and inhibits TNF- $\alpha$ mediated leukotriene synthesis suppressing further inflammation (Barnes, 1998).

TNF- $\alpha$ is a neuroinflammatory mediator (Nogawa et al. 1997; Vesce et al. 2007) which triggers a cascade of events resulting in provoking the expression of cyclo-oxygenase-2 (COX-2) enzyme (Nogawa et al. 1997). Increased COX2 expression results in production of prostaglandin, $\mathrm{PGE}_{2}$, which promotes febrile and behavioral alterations (Hayley et al. 2008). There are a number of publications which provide the evidence for presence of TNF- $\alpha$ in the brain of rodents as well as humans under normal and pathological conditions (Olmos and Llado, 2014). Aminophylline, a competitive non-selective phosphodiesterase inhibitor significantly attenuated( $\mathrm{p}<0.001,4 \mathrm{mg} / \mathrm{kg}$ i.p.) the restrain stress induced behavioral alterations suggesting that pharmacological modulation of TNF- $\alpha$ may be one of the factors for counteracting the stress associated changes in the behaviour. From the above results so obtained, the significant levels of amelioration can be observed with the dose of aminophylline $(4 \mathrm{mg} /$ $\mathrm{kg}$ i.p.; $\mathrm{p}<0.001)$ as compared to the other two doses $(1 \mathrm{mg} / \mathrm{kg}, 2 \mathrm{mg} / \mathrm{kg})$.

In this study, it can be seen that restraining of female rats for three and half hours resulted in significant behavioral alterations which includes decreased 
spontaneous activity, exploratory behaviour and an increased non-social behaviour. The different behavioural parameters are analyzed using various paradigms such as hole board, open field and the social interaction test. Furthermore, to establish the biochemical basis of stress various biochemical parameters such as reduced glutathione, TBARS, SOD and catalase are also estimated, thereby, suggesting that restrain stress induces oxidative stress that leads to neurodegenerative effects.

Therefore, it may be concluded that during stressful conditions, TNF- $\alpha$ expression increases and along with other neuroinflammatory mediators, is responsible for behavioral alterations and aminophylline modulates the TNF- $\alpha$ activity in brain thereby resulting ameliorative potential against restrain stress induced behavioral alterations.

\section{CONCLUSION}

From the present study, it may be proposed that aminophylline modulates restrain stress induced behavioural and biochemical effects and it may be possibly be attributed to alter the TNF- $\alpha$ expression during immobilization stress. The above findings from the study, suggests that aminophylline may be further investigated as a potential anti-anxiety and anti-stress agent.

\section{REFEREN CES}

[1] Abe, T., Nishii, Y., and Okada, Y. (2008) "Aminophylline increases parasternal intercostal muscle Activity during hypoxia in humans," Respiratory Physiology \& Neurobiology, 69-75.

[2] Alleva E., Aloe L., and Bigi S., (1993) "An updated role for nerve growth factor in neurobehavioural regulation of adult vertebrates," Review of Neurosciences, $\mathbf{4}$, 41-62. https://doi.org/10.1515/REVNEURO.1993.4.1.41

[3] Barnes, P.J. (1998) "Mode of action of theophylline: a multiplicity of actions". International Congress Series, 126, 39-45.

[4] Blokland, A., Lieben,C. and Deutz, N.E.,(2002) “Anxiogenic and depressive-like effects, but no cognitive deficits, after repeated moderate tryptophan depletion in the rat," Journal of Psychopharmacology, 16, 39-49. https://doi.org/10.1177/026988110201600112

[5] Brown, G.R. and Nemes, C., (2008) "The exploratory behavior of rats in the holeboard apparatus: Is Head-dipping a valid measure of neophilia". Behavioural Processes, 78, 442-448. https://doi.org/10.1016/j.beproc.2008.02.019

[6] Calamandrei G., Valanzano A. and Alleva E. (1991) "NGF and cholinergic control of behavior: Anticipation and enhancement of scopolamine effects in neonatal mice". Developmental Brain Research, 61, 237-224.

https://doi.org/10.1016/0165-3806(91)90136-7
Ameliorative

Potential of

Aminophylline

In Restrain

Stress Induced

Behavioural and

Biochemical

Alterations 
Kaur, R.

Kaur, M.

Arora, $\mathrm{P}$.
[7] Das, A., Kapoor, K., Sayeepriyadarshani, A.T., Dikshit, M., Palit G., Nath, C. et. al., (2000) "Immobilization stress induced change in brain acetylcholinesterase activity and cognitive function in mice," Pharmacological Research, 42, 213-217. https://doi.org/10.1006/phrs.2000.0678

[8] Deisseroth, A., and Dounce, A.L., (1970) "Presence of high molecular weight form of catalase in enzyme purified from mouse liver," Physiological Reviews, 50, 319-375.

[9] Ellman, G.L. (1959) "Tissue sulfhydryl groups". Archives of Biochemistry and Biophysics, 82, 4867-48677. https://doi.org/10.1016/0003-9861(59)90090-6

[10] Fridovich, I., (1983) "Assaying for superoxide dismutase activity," Annual Review of Pharmacology and Toxicology, 23, 29-222.

[11] Harris, E.D., (1992) "Regulation of antioxidant enzymes". The Journal of Nutrition, 122, 625-626.

[12] Hayley, S., Mangano, E., Strickland, M., Anisman, A.H. (2008) "Lipopolysaccharide and a social stressor influence behaviour, corticosterone and cytokine level. Divergent actions in cyclooxygenase-2 deficient mice and wild type controls," Journal of Neuroimmunology, 197, 29-36. https://doi.org/10.1016/j.jneuroim.2008.03.015

[13] Johnson J.D., Campisi J., Sharkey C.M.,.Kennedy S.L, Nickerson M., Greenwood B.N.et. al. (2005) "Catecholamines mediate stress-induced increases in peripheral and central inflammatory cytokines," Neuroscience, 135(4), 1295-1307. https://doi.org/10.1016/j.neuroscience.2005.06.090

[14] Kaur, R.K., Jaggi, A.S., \& Singh, N. (2010) "Studies on the Effect of Stress Preconditioning in Restrain Stress-induced behavioral alterations," Yakugaku Zasshi 130(2), 215-221. https://doi.org/10.1248/yakushi.130.215

[15] Kumar, P. and Kumar, A.(2009) "Neuroprotective effect of cyclosporine and FK506 against 3-nitropropionic acid induced cognitive dysfunction and glutathione redox in rat: Possible role of nitric oxide," Neuroscience Research, 63, 302-314. https://doi.org/10.1016/j.neures.2009.01.005

[16] Luck H., (1971) "Catalase in Methods of Enzymatic Analysis," Wiley online Library, 885-893.

[17] Madhyastha, S., Prabhu, L.V., Saralaya, V., Pai M.M. and Rai, R. (2008) "Effect of prenatal stress and serotonin depletion on postnatal serotonin metabolism in Wister rats," Iranian Journal of Pharmacology \& Therapeutics, 7 (1), 71-77.

[18] Manchanda, R.K., Jaggi, A.S., \& Singh, N. (2011) "Ameliorative potential of Sodium cromoglycate and diethyldithiocarbamic acid in restraint stress induced behavioral alterations in rats," Pharmaclogical Reports, 63, 54-63.

https://doi.org/10.1016/S1734-1140(11)70398-X 
[19] MillerA.H.,Maletic V., and RaisonC.L.(2009) “Inflammation and Its Discontents: The Role of Cytokines in the Pathophysiology of Major Depression" Biological Psychiatry, 65(9), 732-741. https://doi.org/10.1016/j.biopsych.2008.11.029

[20] Nogawa S., Zhang F., Ross M.E., Iadecola C. (1997) “Cyclo-oxygenase- 2 gene expression in neurons contributes to ischemic brain damage," Journal of Neurosciences, 17(8), 2746-2755.

[21] Olmos, G., \& Llado, J.(2014) "Tumor Necrosis Factor Alpha: A Link between Neuroinflammation and Excitotoxicity," Mediators of Inflammation, 2014, 1-12. https://doi.org/10.1155/2014/861231

[22] Rex, A., Voigt, J.P., Gustedt, C., Beckett, S., and Fink, H., (2004) “Anxiolyticlike profile in Wistar but not Sprague-Dawley rats in the social interaction test," Psychopharmacology, 177, 23-34. https://doi.org/10.1007/s00213-004-1914-7

[23] Roman, E., Gustafsson, L., Berg M. and Nylander, I., (2006) "Behavioral profiles and stress-induced corticosteroid secretion in male wistar rats subjected to short and prolonged periods of maternal separation". Hormones and Behavior, 50, 736-747. https://doi.org/10.1016/j.yhbeh.2006.06.016

[24] Toth, E., Avital, A., Leshem, M., Ritcher-Levin, G., and Braun, K.(2008). "Neonatal and juvenile stress induces changes in adult social behavior without affecting cognitive function," Behavioural Brain Research, 190, 135-139.

https://doi.org/10.1016/j.bbr.2008.02.012

[25] Vassallo R., and Lipsky J. J. (1998) “Theophylline: Recent Advances in the Understanding of Its Mode of Action and Uses in Clinical Practice," Mayo Clinic Process, 73, 346-354. https://doi.org/10.1016/S0025-6196(11)63701-4

[26] Vesce, S., Rossi, D., Brambilla, L. and Volterra, A. (2007) “Glutamate release from astrocytes in physiological conditions and in neurodegenerative disorders characterized by neuroinflammation," International Review of Neurobiology, 82, 57-71. https://doi.org/10.1016/S0074-7742(07)82003-4

[27] Willcox, J.K., Ash, S.L., Catignani, G.L., (2004) “Antioxidants and prevention of chronic disease," Critical Reviews in Food Science and Nutrition, 44, 275-295. https://doi.org/10.1080/10408690490468489

[28] Wills, E.D., (1996) "Mechanisms of lipid peroxide formation in animal tissues," Biochemical Journal, 99(3), 667-676. https://doi.org/10.1042/bj0990667 